\title{
Investigation of the association between dietary fibre, protein and fat with Manganese content in food
}

\author{
Madhura Jayasinghe ${ }^{1 *}$, Binosha Fernando², Subhashinie Senadheera ${ }^{3}$, Pubudu Gunawardene ${ }^{4}$, \\ Somathilaka Ranaweera ${ }^{1}$ \\ ${ }^{1}$ Department of Food Science and Technology, Faculty of Applied Sciences, University of Sri Jayewardenepura, \\ Gangodawila, Nugegoda, Sri Lanka \\ ${ }^{2}$ Centre of Excellence for Alzheimer's disease Research and Care, Sir James McCusker Alzheimer's Disease Research Unit, \\ School of Medical and health Sciences, Edith Cowan University, Joondalup, Australia \\ ${ }^{3}$ Department of Biochemistry, Faculty of Medicine and Allied Sciences, Rajarata University of Sri Lanka, Saliyapura, Sri \\ Lanka \\ ${ }^{4}$ Zooplus AG, Sonnenstraße 15, Munich, Germany
}

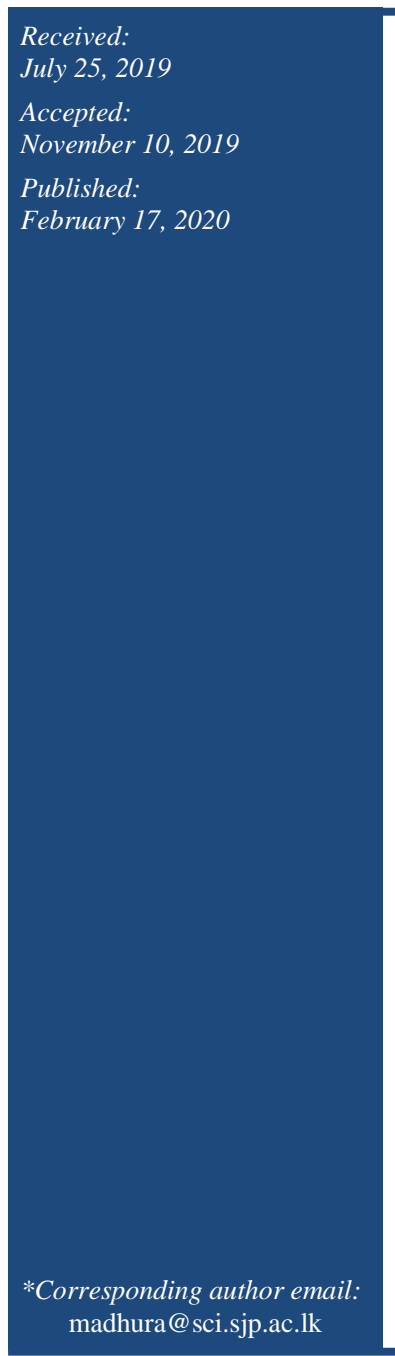

\begin{abstract}
Manganese deficiency may cause severe health disorders and is becoming prevalent in societies that are rapidly urbanising. Determining the Manganese contents and its relationship with the intake of protein, fibre and fats is important; which may allow people to select Manganese rich foods based on their major macronutrients. A crosssectional study including detailed dietary assessment for two weeks, followed by proximate analysis of regularly consumed diets was conducted using 1200 adults from three different social segments as; lecturers/teachers (400), managerial employees in the private sector (400), and houses wives (400). Each social segment was assumed to elicit different lifestyles and different daily Manganese and Macronutrient intake levels. Most frequently consumed food items by them and their respective portion sizes were identified. Those were prepared using mostly practiced cooking methods and chemically analysed for proximate compositions of fat, protein, dietary fibre and Manganese contents. Regression and general liner models were used to estimate the association between protein, fibre and fat intake and Mn levels. The average daily protein, fibre and fat intakes were $53.51,36.85$ and 41.85 grams respectively. The average Manganese intake was 1.87 grams. There were significantly negative association between dietary Manganese levels and fat intake $(\beta=-0.041, p<0.00)$. Increased dietary fat intake was associated with low levels of Manganese $(\beta=-0.041$, $p<0.00)$ for all social segments. Higher protein $(\beta=0.019, p=0.01)$ or fibre intake $(\beta=0.013 \mathrm{p}=0.002)$ reduced the risk of Manganese deficiency. Overall, dietary Manganese elicited a positive correlation with proteins and fibre in foods, but a negative correlation with dietary fat.
\end{abstract}

Keywords: Manganese, Dietary fibre, Fats, Protein

\section{How to cite this:}

Jayasinghe MA, Fernando WMADB, Senadheera SPAS, Gunawardene PP and Ranaweera KKDS, 2020. Investigation of the association between dietary fibre, protein and fat with Manganese content in food. Asian J. Agric. Biol. 8(1):31-37. DOI: 10.35495/ajab.2019.05.214

This is an Open Access article distributed under the terms of the Creative Commons Attribution 3.0 License. (https://creativecommons.org/licenses/by/3.0), which permits unrestricted use, distribution, and reproduction in any medium, provided the original work is properly cited 


\section{Introduction}

Manganese $(\mathrm{Mn})$, is an essential trace nutrient and necessary for the 'Mineral balance' of the human body; can be obtained through the diet. Manganese is vital for a number of biological and physiological processes, metabolism. For example, manganese is crucial for continuation of ionic gradients, cellular and tissue integrity, mitochondrial oxidative phosphorylation and DNA, RNA and protein synthesis (Yoon et al., 2011). Haas and Levin (2012) state that Manganese is a major agent that activate enzymes required for the body to use biotin, thiamine and vitamin $\mathrm{C}$. It is required for the generation of cholesterol and fatty acids during the glucose metabolism. As a cofactor, manganese help to accelerate metabolism of glucose. Manganese is important for the growth and development of normal bone structure and for generating mucopolysaccharides, which are required for healthy joint membranes. Further, Erikson and colleagues (2007) state that Manganese can transfer through placenta during pregnancy to reach a developing fetus than enables balanced growth of the fetus (Erikson et al., 2007).

It is believed that a diet high in protein and fibre and diets with low fat may confer a degree of protection against Mn deficiency. Yet, complete studies directly assessing the relationship between protein and fibre or fat intake by people, and Mn quantity based on different social segments, are not to be found.

Consequently, the major objective of this study was to assess the correlation between dietary protein and fibre or fat intake, and Mn levels of adults in different social segments. We focused on cognitively healthy adults in order to avoid potential differential misclassification bias of dietary intake due to cognitive impairment.

\section{Material and Methods}

\section{Study participants}

This study describes cross-sectional data from 1200 cognitively normal adults who completed structured food frequency questionnaire that helped to assess variety and quantity of nutrients they used. Participants were selected from three different social segments as lecturers/teachers (400), managerial employees in the private sector (400), and houses wives (400). Disproportionate stratified sampling was used, but maximum effort was put to select number of volunteers in compliance with the provincial population distribution in Sri Lanka (Figure 1). As the UK National Nutrition and Dietary Survey (NDNS) collected dietary details from 1724 participants from a population of 60 million (Nelson et al., 1997), the sample size of 1200 was used in the current study was assumed as more than adequate the limit to represent the 21.44 million population's selected three social segments; that might be approximately 7.2 million (Jayasinghe and Ranaweera, 2015). Volunteers selected were aged 24 -45 years at enrolment, and were excluded from the study if they had a history of bipolar disorder, dementia, Parkinson's disease, significant current depression, schizophrenia, cancer; within the last two years and diabetes mellitus, symptomatic stroke, or regular alcohol use.

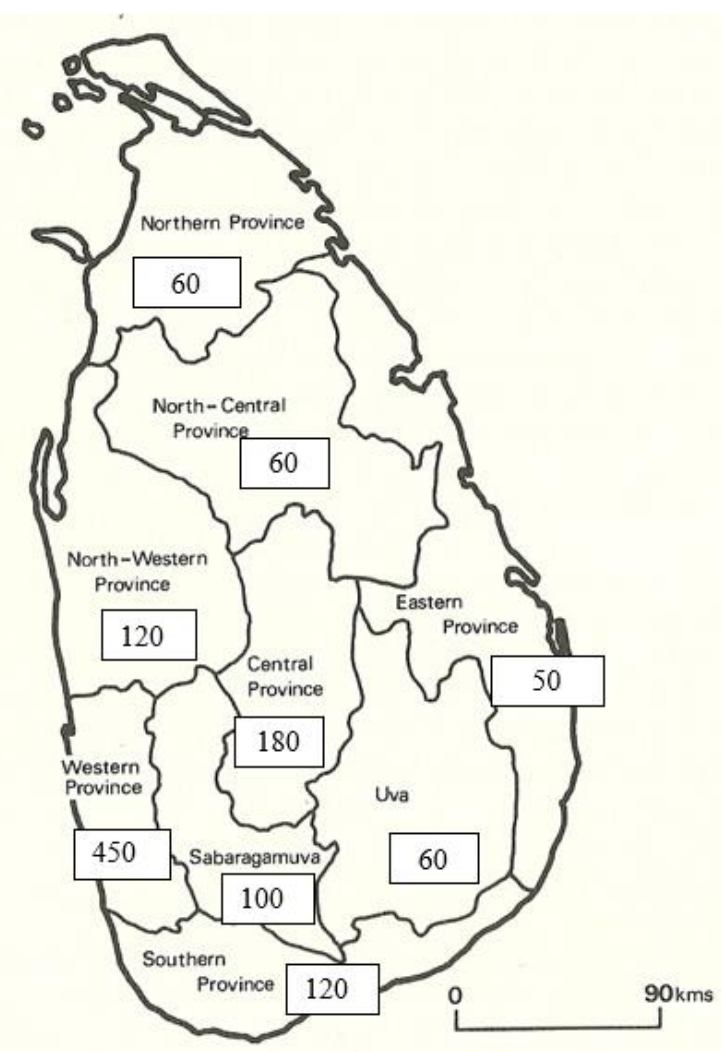

Figure-1: Sample population's distribution

\section{Food frequency questionnaire}

The food frequency questioner (ffq) has 100-item self-administered semi-quantitative questions which assesses usual daily food intake over the preceding 2 weeks. The food composition data used to calculate daily nutrient intake of protein and fibre in grams, and kcal per day energy intake and they were used in 
the current analysis. Food combinations that are most frequently consumed were identified with their relative portion sizes. They were prepared according to mostly practiced cooking methods by Sri Lankans, and chemically analysed for proximate compositions of fat, proteins, dietary fibre and Manganese.

\section{Data collection}

Questionnaires were answered by interviewees. In written questionnaire filling was done by trained interviewers according to the answers provided by interviewees. All individuals represent different 1200 household units.

\section{Preparation of frequently consumed foods by volunteers}

Grains were boiled using rice cooker $\left(99 \pm 2^{\circ} \mathrm{C}\right)$. Pulses were prepared by pressure cooking (121 $\pm 1^{\circ} \mathrm{C}$ ), since it was mostly practiced according to the community survey results. However, to comply with the cooking methods of the rural poor, both grains and pulses samples were made after boiling by fire wood. Average values of sample analysis results were considered. Chicken was prepared as curry and fried. Other ground meats and fish (except anchovy) were prepared as curries. Leafy vegetables were prepared as salads as well as curries. When prepared as salads, scraped coconuts were mixed. Non-leafy vegetables were prepared as curries. Altogether, the most commonly practiced cooking methods of the general public were followed. Whenever a food is being prepared as a curry/gravy, common local spices and condiments are being added in proportions depending on the food item. Fruits were analysed in their raw status.

\section{In-vitro food Sample preparation for micronutrient analysis}

The method of Boisen and Eggum (1991) was followed for this analysis. Each food sample was homogenized at $17300 \mathrm{rpm}$ for $2 \mathrm{~min}$ (ULTRATURRAX®) in $25 \mathrm{~mL}$ of phosphate buffer (pH 6.8). Digestion with $200 \mu \mathrm{L} \alpha$-amylase in water bath at $37.5^{\circ} \mathrm{C}$ for 30 minutes was carried on followed by the addition of $20 \mathrm{~mL}$ of $0.2 \mathrm{M} \mathrm{HCl}\left(37.5^{\circ} \mathrm{C}\right)$. Then, the $\mathrm{pH}$ was adjusted to 1.5 (Thermo Electron Corporation Orion 410A+) and mixtures were digested with $0.2 \mathrm{~g}$ of pepsin (Fisons, England) at $40.0^{\circ} \mathrm{C}$ in a shaking water bath (EYELA Uni Thermo Shaker NTS-1300) for 1 hour. After allowing cooling to the room temperature, $\mathrm{pH}$ was adjusted to 7.8 and
Pancreatin 0.2 g (EC No 232-468-9 Sigma-Aldrich, USA) was added to each sample followed by $100 \mu \mathrm{L}$ of bile salt and digested at $37.8^{\circ} \mathrm{C}$ for 2 hours with continuous shaking.

Digested samples were centrifuged until there was a clear separation of pellet and the supernatant. Clear supernatants were pipette out to obtain final samples.

\section{Determination of mineral contents}

The method of Petrovich and Neto (2007) was followed for this analysis. The flow-injection system contained an Ismatec (Zurich, Switzerland) IPC-8 multichannel peristaltic pump, attached with Tygon TM pumping tubes, a Perkin Elmer (Shelton, CT, USA) Analyst 100 spectrometer embedded with a deuterium lamp, background corrector (Delft, The Netherlands). A BD 111 recorder with a manual injector and a polyethylene tube (i.d. $=0.8 \mathrm{~mm}$ ) with coiled reactors with relevant accessories were included. Accurately measured three replicates were used for Manganese. The atomic absorption spectrophotometer was equipped with flame and graphite furnace with air-acetylene flame. Acetylene $1.8 \mathrm{~L} / \mathrm{min}$, air $15 \mathrm{~L} / \mathrm{min}$, the inert argon gas flow and the temperature parameters were followed. The monochromator was adjusted to $422.7 \mathrm{~nm}$ and the slit-width to $0.7 \mathrm{~nm}$. Atomic signal was measured in peak height mode. A PerkinElmer LuminaTM multielementar hollow cathode lamp (P/N N3050218) was used for the determination of atom concentrations at lamp current of $30 \mathrm{~mA}$.

\section{Determination of fat, fibre, and protein}

The fat and dietary fibre levels were determined by Croon and Guchs (1980) and by the method of Asp et al. (1983) respectively. The crude protein content was by Kjeldahl method using Copper/Selenium catalysts (AOAC, 1987).

\section{Statistical analysis}

Statistical analyses was performed using SPSS (IBM) Statistics package 22 (Windows Vista -SPSS Inc., Chicago, IL, USA), with a p-value of 0.05 or smaller determining a significant result. Means with standard deviations and percentage values are provided for the whole cohort, and subgroups of cohorts were stratified by dietary protein, fat or fibre intake (in tertiles) and by job category. All three independent variables (fibre intake, fat intake and protein intake) were divided in to different tertiles, with tertile 1 was denoted by the lowest intake. At the beginning, 
general linear models were used to assess relationships between the independent variable tertiles (protein, fibre, fat) and the continuous dependent variables (Mn intake level). The general linear models included age, gender, years of education ( $\leq 12$ and $>12$ years), place of living (Colombo or other), body mass index (BMI; calculated as weight in kilograms divided by height in meters squared) and energy intake (kcal) as covariates.

With the cohort stratified by job, multiple linear regression analyses were conducted to crosssectionally examine the relationship between protein, fibre and fat intake (independent variable) and $\mathrm{Mn}$ level (dependent variable). The most common confounding variables were entered into this models as covariates, specifically; body mass index (BMI), years of education ( $\leq 12$ years, or $>12$ years), gender, energy intake, and age.

\section{Results and Discussion}

Results of general linear model and linear regression analysis and linear regressions examining suggest that participants who consume more fat may tend to have food that are not enriched in Mn. Further participants who consume fibre and protein rich food may have a higher probability to gain higher quantity of Mn with their diets.

This cohort comprised of 1200 cognitively normal participants (50\% male) with average age of 36.65 years. All participants were born in Sri Lanka, approximately $23 \%$ had 12 or less years of education. The cohort had an average body mass index of 26.72 $\pm 7.2 \mathrm{~kg} / \mathrm{m} 2$, with an average daily energy intake of $2490.51 \pm 803.11 \mathrm{KCal}$, mean daily protein, fibre and fat intakes of $53.51 \quad 36.85$ and 41.85 grams respectively, and an average $\mathrm{Mn}$ intake was 1.87 grams (Table 1).

General linear models; F- and p-values shown. Linear regression Beta values and $\mathrm{P}$ values shown, Model adjusted for age, gender, years of education, Job category, Place of live (Colombo Vs. others, body mass index, and energy intake. $\mathrm{P}<0.05$ is considered as significant.

In general linear models used to assess the relationship between intakes of macronutrients protein, fibre or fat (categorical variable), and the levels of $\mathrm{Mn}$ (continuous variable); significant associations were observed (Table 2) between fibre and fat intake and Mn levels of the body. In the linear regression used to assess the correlation between $\mathrm{Mn}$ level (continuous) of the body and intake of protein, fibre or fat (continuous); a significant negative association was observed between $\mathrm{Mn}$ levels and fat intake $(\beta=-0.041, p<0.00)$. However, association between protein $(\beta=0.019, \mathrm{p}=0.01)$ or fibre intake $(\beta=0.013 \mathrm{p}=0.002)$ and Mn levels were significant and positive. Thus, for this cohort the more grams per day of fat participants consumed, will have low level of $\mathrm{Mn}$ in their body.

Table-1: Descriptive statistics for entire cohort who completed the survey

\begin{tabular}{|c|c|c|c|c|c|}
\hline & Entire cohort & Housewives & Teachers/Lecturers & $\begin{array}{c}\text { Private sector } \\
\text { managers }\end{array}$ & \begin{tabular}{|c|}
$\mathbf{P}$ \\
value \\
\end{tabular} \\
\hline Age(y) & $36.45 \pm 5.5$ & $33.45 \pm 5.89$ & $38.1 \pm 5.02$ & $37.8 \pm 4.28$ & 0.009 \\
\hline Gender, Male (\%) & 50 & 0 & 50 & 50 & \\
\hline Education $>12$ Grade $(\%)$ & 76.7 & 60 & 100 & 90 & $<0.00$ \\
\hline Daily Fat intake(g/day) & $41.82 \pm 10.91$ & $46 \pm 9.06$ & $32.87 \pm 5.85$ & $46.59 \pm 8.8$ & $<0.00$ \\
\hline Daily fibre intake(g/day) & $36.85 \pm 15$ & $34.63 \pm 4.78$ & $54.96 \pm 4.67$ & $20.99 \pm 6.3$ & $<0.00$ \\
\hline Daily protein intake (g/day) & $53.91 \pm 13.8$ & $63.23 \pm 5.77$ & $36.03 \pm 3.49$ & $62.49 \pm 6.37$ & $<0.00$ \\
\hline Daily Mn Intake(g/day) & $1.87 \pm 0.4$ & $1.92 \pm 0.35$ & $2.103 \pm 0.35$ & $1.59 \pm 0.33$ & $<0.00$ \\
\hline Body Mass Index $\left(\mathrm{kg} / \mathrm{m}^{2}\right)^{*}$ & $26.72 \pm 7.2$ & $26.63 \pm 6.41$ & $26.31 \pm 7.29$ & $27.21 \pm 6.88$ & \\
\hline Energy intake(kCal) & $2490.51 \pm 803.11$ & $2203.15 \pm 728.62$ & $2309.58 \pm 564.83$ & $2958.82 \pm 708.91$ & \\
\hline
\end{tabular}

Unless otherwise described, data are presented as mean \pm standard deviation of the mean. Bold indicates statistical significance ( $<<0.01$ ); characteristics compared using Analysis of variance (ANOVA) for continuous variables and $\chi^{2}$ for categorical variables. Body Mass Index calculated as weight in kilos divided by height taken in meters squared. Abbreviations: g/day, grams per day; kcal, kilocalories; kg, kilograms; $\mathrm{m}^{2}$, meters squared; y, years. 
Following stratification of the cohort by dietary protein, fibre and fat intake tertiles, general linear model analysis revealed that significant difference in Mn levels between participants who had low and high, and medium and high protein intake. There were significant difference in Mn levels between participants who had low and medium, and low and high fibre intake. Further revealed that significant difference in Mn levels between participants who had low and medium, low and high, and medium and high fat intake (Table 3). Together, results indicates participants who had low fibre or protein intake may have low level of Mn levels (Table 2 and Table 3). In contrast, results suggests that fat content may affect the level of the Mn of the body regardless of their level of intake (Table 2 and Table 3).

Table-3: Relationship between low, medium and high intake of protein, fibre, Fat and Mn levels in the entire cohort using general linear model.

\begin{tabular}{|c|c|c|c|}
\hline & $\begin{array}{c}\text { Tertile 1 Vs } \\
\text { Tertile2 }\end{array}$ & $\begin{array}{c}\text { Tertile 1 Vs } \\
\text { Tertile 3 }\end{array}$ & $\begin{array}{c}\text { Tertile 2 Vs } \\
\text { Tertile 3 }\end{array}$ \\
\hline Protein & .858 & $\mathbf{. 0 0 0}$ & $\mathbf{. 0 0 0}$ \\
\hline Fibre & $\mathbf{. 0 0 0}$ & $\mathbf{. 0 0 0}$ & .112 \\
\hline Fat & $\mathbf{. 0 0 0}$ & $\mathbf{. 0 0 0}$ & $\mathbf{. 0 0 0}$ \\
\hline
\end{tabular}

General linear models; p-values shown. Results of multiple comparison, Model adjusted for age, gender, years of education, Job category, Place of live ( Colombo Vs others, body mass index, and energy intake. $\mathrm{P}<0.05$ is considered as significant, Protein: low (0-46.43g), medium (46.4-63.07g), high $(>63.07 \mathrm{~g})$; Fibre: low $(0-29.37 \mathrm{~g})$, medium (29.37$45.03 \mathrm{~g})$, high (>45.03g); Fat: low (0-36.99g), medium (36.99-45.33g), high (>45.33)

Following stratification of the cohort by the job category, the cross-sectional linear regression analysis assessing the association between intake of protein, fibre or fat, and the levels of $\mathrm{Mn}$ as continuous variables showed; a significant negative association between Mn levels and protein intake in house wife's (Table 4). However, this was not seen among Teachers and private sector managers. House wives and teachers had significant positive association between $\mathrm{Mn}$ level and fibre intake. However, this was not seen in private sector managers. Results also suggested that private sector managers have negative association between fat intake and Mn levels which was not seen among teachers and house wives (Table 4).
Taken together; this cohort suggest that participants who consume more fat may tend to have food that are not enriched in Mn. Further participants who consume fibre and protein food may have a higher probability to have higher quantity of $\mathrm{Mn}$.

Table-4: Results of linear regressions examining the association between dietary intake of protein, fibre, Fat and Mn level in the entire cohort stratified by house wives, Teachers and Managers in private sector.

\begin{tabular}{|c|c|c|c|c|c|c|}
\hline & \multicolumn{2}{|c|}{ House wife's } & \multicolumn{2}{c|}{ Teachers } & \multicolumn{2}{c|}{$\begin{array}{c}\text { Private sector } \\
\text { managers }\end{array}$} \\
\hline & $\beta$ & P value & $\beta$ & P value & $\beta$ & $\begin{array}{c}\text { P } \\
\text { value }\end{array}$ \\
\hline Protein & -.045 & $\mathbf{. 0 0 2}$ & .008 & .487 & -.011 & .210 \\
\hline Fibre & .031 & $\mathbf{. 0 1 0}$ & -.062 & $\mathbf{. 0 0 2}$ & .010 & .076 \\
\hline Fat & .007 & .186 & -.004 & .740 & -.024 & $\mathbf{. 0 0 0}$ \\
\hline
\end{tabular}

Standardized $\beta$ values shown

Linear regression Beta values and $\mathrm{P}$ values shown, Model adjusted for age, gender, years of education, Job category, Place of live (Colombo Vs others), body mass index, and energy intake. $\mathrm{P}<0.05$ is considered as significant.

Results of general linear model and linear regression analysis and linear regressions examining suggest that participants who consume more fat may tend to have food that are not enriched in Mn. Further participants who consume fibre and protein food may have a higher probability to have higher quantity of $\mathrm{Mn}$ in their diets.

According our knowledge, no other studies directly determining the relationship between protein and fibre intake, and Manganese has been done. Greger and Snedeker (1980) states that, there is no significant correlation between protein intake levels and Manganese absorption levels to the blood, although It does not describe how Manganese is associated with proteins in natural or processed food sources. Likewise, Manganese's association with dietary fat in available foods are not studied, but some findings done using rat models suggest that; biliary manganese content in rats does not have a correlation with dietary fat (Malecki et al., 1996). A previous study conducted to determine mineral compositions in highly fibrous food in the Indian subcontinent revels that, many green leafy vegetables contain high manganese content; allowing to think of 
a possible positive correlation between manganese and dietary fibre (Singh et al., 2001).

There are observable qualitative and qualitative differences in food intakes by different social segments, primarily based on their lifestyle. As a $n$ example; a typical managerial level employee who usually spends a busy lifestyle; may take in a high protein, high fat, but low fibre diet whereas among teachers/lecturers; fat and protein contents may become relatively low and dietary fibre content was observed to be higher, as they are assumed to have more time in food selection and preparation (Jayasinghe and Ranaweera, 2015). Manganese being a rich component in many leafy vegetables, assumed to have a positive relationship with dietary fibre content. Hence, busier the lifestyles that are resulting in limited time for plant food preparation and consumption can lead up to Manganese deficiency. People who are working/living in urban areas who are frequent consumers of fast and processed foods that lack in plant origin foods, should be warned of Manganese deficiency consequences. Green leafy vegetables, non-leafy vegetables, some root crops and whole grains that are excellent sources of Manganese should be incorporated more into regular diets to minimize the risk of Mn deficiency.

In children, prolonged manganese deficiency may cause blindness or even paralysis. In adults; manganese deficiency can lead in to hearing problems and dizziness. Low manganese levels in blood serum can result in decreased function of the pancreatic cells (Rude, 1998). From the nutritional point of view, manganese may be one of the least toxic minerals. There is no known natural toxicity from manganese in food, as mentioned by the World Health Organization in 2010.

Change of lifestyles which have led to consume more fast food and unawareness of how to balance nutrients in a diet, may have resulted in lower intakes of Manganese by these social segments in Sri Lanka, which might influence higher rates of several noncommunicable diseases related to Mn deficiency in the society if continued in the same fashion.

\section{Conclusion}

Results of general linear model and linear regression analysis and linear regressions examining suggest that participants who consume more fat may tend to have food that are not enriched in Mn. Further participants who consume fibre and protein rich food would have a higher probability to have higher quantity of $\mathrm{Mn}$ in their diets.

\section{Acknowledgement}

We express our sincere gratitude to Dr. Asitha Cooray and all staff members at the "Instrument Centre" at Faculty of Applied Sciences, University of Sri Jayewardenepura, Sri Lanka.

\section{Disclaimer: None.}

Conflict of Interest: None.

Source of Funding: None.

\section{References}

Asp NG, Johansson CG, Hallmer H and Siljestroem M, 1983. Rapid enzymic assay of insoluble and soluble dietary fiber. J. Agric. Food Chem. 31(3): 476-482.

AOAC (Association of Official Analytical Chemists), 1987. Official Methods of Analysis of the AOAC; AOAC: Washington DC, 7.033.

Boisen S and Eggum BO, 1991. Critical evaluation of in vitro methods for estimating digestibility in simple-stomach animals. Nutr. Res. Rev. 4(1): 141-162.

Croon LB and Guchs G, 1980. Crude fat analysis of different flours and flour products. Var Foda. 32: 425-427.

Erikson KM, Thompson K, Aschner J and Aschner M, 2007. Manganese neurotoxicity: a focus on the neonate. Pharmacol. Therap. 113(2): 369-377.

Greger JL and Snedeker SM, 1980. Effect of dietary protein and phosphorus levels on the utilization of zinc, copper and manganese by adult males. J. Nutr. 110(11): .2243-2253.

Haas E and Levin B, 2012. Staying healthy with nutrition, rev: the complete guide to diet and nutritional medicine. Celestial arts, USA.

Jayasinghe KWMA and Ranaweera KKDS, 2015. Nutrition Assessment of Several Sects in the Sri Lankan Community. Population. 140(42): 58.

Malecki EA, Radzanowski GM, Radzanowski TJ, Gallaher DD and Greger JL, 1996. Biliary manganese excretion in conscious rats is affected by acute and chronic manganese intake but not by dietary fat. J. Nutr. 126(2): 489-498. 
Nelson M, Atkinson M and Meyer J, 1997. A photographic atlas of food portion sizes. Ministry of Agriculture, Fisheries and Food, London, UK.

Petrovich MB and Neto JAG, 2007. Direct determination of calcium in milk by atomic absorption spectrometry using flow-injection analysis. Eclética Química. 32(3): 25-30.

Rude RK, 1998. Magnesium deficiency: a cause of heterogeneous disease in humans. J. Bone Mineral Res. 13(4): 749-758.

Singh G, Kawatra A and Sehgal S, 2001. Nutritional composition of selected green leafy vegetables, herbs and carrots. Plant Foods Human Nutr. 56(4): 359-364.

Yoon M, Schroeter JD, Nong A, Taylor MD, Dorman DC, Andersen ME and Clewell HJ, 2011. Physiologically based pharmacokinetic modelling of fetal and neonatal manganese exposure in humans: describing manganese homeostasis during development. Toxicol. Sci. 122(2): 297316.

\section{Contribution of Authors}

Jayasinghe M: Conducted the study and wrote the article

Fernando B: Conducted the statistical analysis of data

Senadheera S: Helped in biochemical analysis methods and write up

Gunawardene P: Supplied information technology help and also helped to conduct the community survey and write up

Ranaweera S: Supervised the research and final approval of manuscript 